assessing exercise induced bronchospasm in clinical practice. J Allergy Clin Immunol 1979;69(6):609-11.

${ }^{2}$ Godfrey S. Exercise and asthma. In: Clark T, Godfrey S, eds. Asthma. London: Chapman and Hall, 1983:61.

${ }^{3}$ Eggleston PA, Guerrant JL. A standardised method of evaluating exercise-induced asthma. J Allergy Clin Immunol 1976;58:414-25.

4 Anderson H, Bailey P, Cooper J, Palmer J, West S. Medical care of asthma and wheezing illness in children: a community survey. J Epidemiol Community Health 1983;37:180-6.

5 Wilson BA, Evans TN. Standardization of work intensity for evaluation of exercise-induced bronchoconstriction. Eur $J$ Applied Physiol 1981;47:289-94.

${ }^{6}$ Godfrey S, Silverman M, Anderson S. The use of the treadmill for assessing EIA and the effect of varying the severity and duration of exercise. Pediatrics 1975;56(suppl):893-9.

Correspondence to Professor R D G Milner, University Department of Paediatrics, Children's Hospital, Sheffield S10 2TH, England.

Received 24 May 1986

\title{
High aluminium content of infant milk formulas
}

\author{
R WEINTRAUB, G HAMS, M MEERKIN, AND A R ROSENBERG
}

Departments of Nephrology and Clinical Chemistry, The Prince of Wales Children's Hospital, Sydney, New South Wales, Australia

SUMMARY The aluminium content of several commercially available infant milk formulas was measured by electrothermal atomic absorption spectrometry. Results were compared with those for fresh breast milk, cow's milk, and local tap water. Differences in aluminium concentration of greater than 150-fold were found, with the lowest concentrations in breast milk.

Because of its ubiquitous nature, aluminium has not traditionally been regarded as an essential trace element. ${ }^{1}$ No cases of aluminium deficiency have been reported and minimum daily requirements for different ages are unknown. Fluids yielding as little as 7.5-15 $\mu \mathrm{g}$ of aluminium per day have been used recently without detriment, however, in infants receiving long term total parenteral nutrition. ${ }^{2}$

Aluminium toxicity in patients with chronic renal insufficiency undergoing haemodialysis or ingesting large quantities of phosphate binding gels is well recognised. ${ }^{3}$ Recently, the high aluminium content of a proprietary milk formula was implicated as the cause of aluminium toxicity in two infants with neonatal uraemia. ${ }^{4}$ In this paper we report the results of the measurement of aluminium in a variety of infant feeds.

\section{Methods}

Sample collection and preparation. Preprepared liquid and powdered formulas were sampled either directly from their glass containers or, in the case of preparations in cans, by collecting aliquots into acid washed polystyrene tubes. Each feed was sampled on two occasions and, where possible, from different batches. Breast milk was collected by lactating mothers directly into acid washed polystyrene tubes, using a no touch technique.

The powders were reconstituted in the laboratory by adding distilled, double deionised (aluminium free) water, using acid washed volumetric apparatus, to portions of accurately weighed milk powder.

Aluminium analysis. Aluminium was assayed by graphite furnace atomic absorption spectrometry employing a Varian Techtron AA975 and GTA 95 with autosampler.

All samples were initially diluted in the ratio of 1 volume of sample to $14 \cdot 2$ volumes of $0 \cdot 3 \%$ analytical grade hydrochloric acid on an automatic diluter.

The aluminium content of samples was quantitated by the method of standard additions to allow for the variation in instrument response caused by the different sample matrices. Typically, a single random representative sample was used to generate a standard additions calibration curve for each analytical run. Subsequent samples in the run were quantitated by comparison with this curve. Samples yielding a mean peak height absorbance greater than the highest calibration point were further diluted with $0 \cdot 3 \%$ hydrochloric acid until they fell within the calibration range.

The analytical technique was controlled with in house' aqueous and serum based control materials (method coefficient of variation at $80 \mu \mathrm{g} / \mathrm{l}$ was roughly $10 \%$, run to run) and by participation in a national aluminium analysis quality control survey (Department of Applied Biology, Royal Melbourne Institute of Technology).

The spectrometer was operated in peak height 
Table Comparative aluminium content of infant feeds

\begin{tabular}{|c|c|c|c|c|}
\hline \multirow[t]{2}{*}{ Sample } & \multicolumn{2}{|c|}{ Type of feed +} & \multirow{2}{*}{$\begin{array}{l}\text { Aluminium content } \\
(\mu g / \text { litre of feed }) \ddagger\end{array}$} & \multirow[t]{2}{*}{ Country of origin } \\
\hline & $\begin{array}{l}\text { Powder } \\
(\mu g / g)\end{array}$ & $\begin{array}{l}\text { Liquid } \\
(\mu g / m l)\end{array}$ & & \\
\hline Breast milk & & 0.03 & 30 & \\
\hline $5 \%$ glucose & & 0.04 & 35 & \\
\hline Tap water (four readings) & & $0 \cdot 04$ & 40 & \\
\hline Glucose-electrolyte mixture & & 0.04 & 40 & \\
\hline Pasteurised cow's milk & & $0 \cdot 09$ & 95 & Australia \\
\hline 'De-Lact Infant'* & $0 \cdot 50$ & & 105 & Australia \\
\hline 'Lactogen' & & $0 \cdot 17$ & 105 & Australia \\
\hline 'S26”* & & $0 \cdot 14$ & 125 & United States \\
\hline 'Digestelact'* & $1 \cdot 01$ & & 165 & Australia \\
\hline 'Similac' & & $0 \cdot 20$ & 200 & Australia \\
\hline 'Alfare' & $1 \cdot 85$ & & 315 & Switzerland \\
\hline 'Enfalac Premature' & $2 \cdot 17$ & & 335 & Canada \\
\hline 'Nan’* & & $0 \cdot 34$ & 345 & Australia \\
\hline 'Glucose Nutramigen'* & $11 \cdot 49$ & & 1725 & Australia \\
\hline 'Pregestimil' & $11 \cdot 80$ & & 1780 & United States \\
\hline 'Isomil' & & $3 \cdot 74$ & 1890 & United States \\
\hline 'Prosobee' & & $10 \cdot 02$ & 5030 & Australia \\
\hline
\end{tabular}

${ }^{*}$ Samples taken from different batches.

†Aluminium content in $\mu \mathrm{g} / \mathrm{g}$ (powder) or $\mu \mathrm{g} / \mathrm{ml}$ (liquid) of feed. Mean of two measurements taken on separate occasions.

$\ddagger$ The calculated aluminium content per litre of feed diluted according to the manufacturers' recommendations (to $20 \mathrm{kcal} / 30 \mathrm{ml}$ ) with water assumed to contain $40 \mu \mathrm{g}$ /litre of aluminium (using the measurements in column 1).

mode with no background correction required. Pyrolytic furnace tubes were used.

Contamination was controlled by ensuring that the peak height absorbance of a blank firing of $0.3 \%$ hydrochloric acid did not exceed 0.02 units relative to an air firing yielding a visually flat baseline.

\section{Results}

The results are shown in the Table. Fresh breast milk, $5 \%$ glucose, and a glucose-electrolyte mixture (both prepared in the formula room of our hospital) were found to have similarly low concentrations of aluminium comparable with known hospital tap water concentration.

Among the milk feeds, the mean concentration of aluminium ranged from 0.09 to $10.02 \mu \mathrm{g} / \mathrm{ml}$ for liquid feeds and 0.23 to $11.80 \mu \mathrm{g} / \mathrm{g}$ for powdered feeds. Compared with a litre of breast milk there was an increase of up to 165 -fold in aluminium content per litre of reconstituted feed. Depending on the formula used, infants drinking a litre of milk daily would be exposed to between 30 and $5000 \mu \mathrm{g}$ of aluminium per day.

Batch to batch variation and country of origin of the formulas did not seem to influence our results.

\section{Discussion}

Aluminium intoxication is now recognised as the cause of a progressive encephalopathy, vitamin D resistant osteomalacia, and one form of anaemia in the presence of chronic renal insufficiency. ${ }^{3}$ Although these manifestations of toxicity were initially recognised in adults with uraemia undergoing haemodialysis, they were subsequently described in children who were receiving large doses of aluminium containing phosphate binding agents but who did not yet require dialysis. ${ }^{5}$

Less severe forms of neurological and intellectual dysfunction in infants developing chronic renal failure in the first year of life are well known. In fact, in one major study 20 of 23 such children were found to have developmental delay, microcephaly, hypotonia, dyskinesia, seizures, and electroencephalographic abnormalities on subsequent follow up. ${ }^{6}$ Poor nutrition, raised serum parathyroid hormone concentration, subsceptibility of the infant brain to the uraemic environment, and aluminium toxicity were suggested as causes; $;^{6}$ the possibility that the aluminium was derived from infant formulas was not considered.

More recently, cerebral aluminium accumulation has been documented in two infants with neonatal uraemia who developed a progressive and fatal encephalopathy in the absence of phosphate binding gels or dialysis with water appreciably contaminated with aluminium. ${ }^{4}$ Both infants were fed with a proprietary milk formula that was found to contain high concentrations of aluminium relative to breast milk.

Our results confirm that infants may be exposed 
to appreciable amounts of aluminium from a variety of proprietary milk formulas, some of which contain more than 15 times the concentration of aluminium already implicated in cerebral toxicity. ${ }^{4}$ This source of exogenous aluminium may contribute to other recognised forms of neurological and intellectual dysfunction in infants with chronic renal insufficiency. The effects of exposure to large quantities of ingested aluminium in infants with lesser degrees of renal impairment or normal renal function remain to be documented.

By comparison with phosphate binding gels, the total aluminium content of infant milk formulas is only modest. In the absence of other commonly recognised risk factors cerebral toxicity may therefore reflect a greater bioavailability of aluminium in milk formulas or an increased uptake of aluminium by the immature brain.

The authors gratefully acknowledge the cooperation of Sister Barton-Bishop for her help with the feeds and Mrs L Beer for the preparation of the manuscript.

\section{References}

${ }^{1}$ Golden MHN. Trace elements in human nutrition. Hum Nutr Clin Nutr 1982;36:185-202.

${ }^{2}$ Klein GL, Berquist WE, Ament ME, Coburn JW, Miller NL, Alfrey AC. Hepatic aluminium accumulation in children on total parenteral nutrition. Journal of Pediatric Gastroenterology and Nutrition 1984;3:740-3.

3 Willis MR, Savory J. Aluminium poisoning: dialysis encephalopathy, osteomalacia and anaemia. Lancet 1983;ii:29-34.

${ }^{4}$ Freundlich M, Zilleruelo G, Abitbol C, Strauss J. Infant formula as a cause of aluminium toxicity in neonatal uraemia. Lancet 1985;ii:527-9.

5 Foley CM, Polinsky MS, Gruskin AB, Baluarte NZ, Grover WD. Encephalopathy in infants and children with chronic renal disease. Arch Neurol 1981;38:656-8.

6 Rotundo A, Nevins TE, Lipton M, Lockman LA, Mauer SM, Michael AF. Progressive encephalopathy in children with chronic renal insufficiency in infancy. Kidney Int 1982;21: 486-91.

Correspondence to Dr A R Rosenberg, The Prince of Wales Children's Hospital, High Street, Randwick, New South Wales 2031, Australia.

Received 29 April 1986 